\title{
Las escalas de análisis en los estudios sobre el pasado reciente: a modo de introducción
}

\section{The scales of analysis in studies of recent past: an introduction}

\author{
Gabriela Águila \\ CESOR-ISHIR \\ Consejo Nacional de Investigaciones \\ Científicas y Técnicas \\ Universidad Nacional de Rosario \\ (Argentina) \\ gbaguila@gmail.com
}

La atención hacia el problema de las escalas de análisis no es nueva en los estudios sobre el pasado reciente que se vienen realizando en nuestro país desde hace al menos una década. Al tiempo que se definían los contornos de la llamada Historia Reciente y se multiplicaban las indagaciones sobre ese tramo del pasado más cercano, resultó cada vez más evidente que uno de los sesgos reiterados en la bibliografía disponible era el predominio de una mirada "nacional" o, más bien, de abordajes centrados en la realidad capitalina o bonaerense y que, generalizados en forma muchas veces simplificadora, soslayaban lo acaecido en otros espacios regionales o locales. Cuestionamientos a este tipo de perspectivas -denominadas muchas veces "porteñocéntricas"- se han planteado con insistencia en diversos trabajos y balances historiográficos publicados en los últimos años. ${ }^{1}$

1. ÁGUILA, Gabriela, "La dictadura militar argentina: interpretaciones, problemas, debates”, en Páginas. Revista 
Conviene mencionar que en nuestro país la construcción de una historiografía renovada estuvo vinculada, entre otros desarrollos, a los estudios regionales y locales. Ello ha sido muy visible para momentos donde la integración nacional aún era débil o donde las realidades $\mathrm{y}$ articulaciones regionales ostentaron rasgos diferenciados, particularmente en el siglo XIX y los inicios del siglo XX. ${ }^{2}$ Para estos períodos y para los problemas que los atraviesan no sólo se acrecentaron las investigaciones de base localregional sino que se verificó una sostenida preocupación por poner en debate algunas categorías o conceptos -región, historia local, historia regional- y/o su pertinencia teórica y metodológica, así como reflexionar sobre los

digital de la Escuela de Historia, Rosario, mayo-agosto de 2008, Año 1, No 1, UNR. Disponible en: <http://paginas. rosario-conicet.gov.ar/ojs/index.php/RevPaginas/article/ view/9>;JENSEN, Silvina, "Diálogos entre la historia local y la historia reciente en la Argentina. Bahía Blanca durante la última dictadura militar”, en REY TRISTÁN, Eduardo y CALVO GONZÁLEZ, Patricia (compiladores) 200 años de Iberoamérica (1810-2010). Congreso Internacional: Actas del XIV Encuentro de Latinoamericanistas Españoles, Universidad de Santiago de Compostela, 2010. Disponible en: <http://hal.archives-ouvertes.fr/file/index/ docid/531187/filename/AT10_Jensen.pdf> [Consulta: 15 marzo 2015]; KOTLER, Rubén I., "A modo del prólogo. ¿Una historia "nacional" del movimiento de derechos humanos de Argentina? Apuntes para el debate", en KOTLER, Rubén I. (compilador) En el país del si me acuerdo. Los orígenes nacionales e internacionales del movimiento de derechos humanos argentino: de la dictadura a la transición, Imago Mundi, Buenos Aires, 2014.

2. La centralidad de ciertos temas y períodos en el desarrollo de una historia regional y local que pretendía poner en cuestión visiones homogeneizadoras de alcance "nacional" (en particular, en lo que respecta al estudio de dinámicas regionales y provinciales en el proceso de conformación del estado nacional), fue ampliándose temporalmente hacia los siglos coloniales tanto como hacia algunos fenómenos de la primera mitad del siglo $\mathrm{XX}$, como el peronismo.

92 modos de hacer historia desde tales escalas. ${ }^{3}$

Si bien esa historiografía local-regional no se ha ocupado de procesos históricos más actuales o incluso ha desatendido tales problemáticas, ${ }^{4}$ lo cierto es que dichas derivas se han manifestado también en el campo de la Historia Reciente. Esto refiere a factores de diverso orden, entre los que deben ser reseñados la preeminencia de la historia regional o local en algunos espacios académicos, que incluyó a los estudios sobre el pasado reciente ${ }^{5}$ tanto como la influencia de tendencias más generalizadas

3. $\mathrm{Al}$ respecto véase BANDIERI, Susana, "La dimensión regional como alternativa analítica para pensar otros espacios y nuevas periodizaciones", en BANDIERI, Susana, BLANCO, Graciela, BLANCO, Mónica (coordinadoras) Las escalas de la historia comparada, T. II: Empresas y empresarios. La cuestión regional, Miño y Dávila, Buenos Aires, 2008; DALLA CORTE, Gabriela y FERNÁNDEZ, Sandra (compiladoras) Lugares para la historia. Espacio, Historia regional e Historia local en los estudios contemporáneos, UNR Editora, Rosario, 2001; FERNÁNDEZ, Sandra, "El revés de la trama: contexto y problemas de la historia regional y local", en FERNÁNDEZ, Sandra (compiladora) Más allá del territorio. La historia regional y local como problema. Discusiones, balances y proyecciones, Prohistoria Ediciones, Rosario, 2007.

4. Silvina Jensen ha sostenido que, con algunas excepciones, "la Historia Regional ha permanecido bastante reacia a incorporar al pasado reciente como objeto de estudio, para interrogarlo desde el potencial teórico-metodológico que ofrecen las nuevas formas de hacer Historia regional y local". Vid., JENSEN, Silvina, "Diálogos entre entre la historia local y la historia reciente en la Argentina...", Op. Cit., p. 1434.

5. En una producción que se hace sobre y desde el interior del país, por fuera de los centros académicos dominantes. Al respecto ORTIZ BERGIA, María José, "Los usos de las escalas espaciales y las prácticas historiográficas en el interior de la Argentina: un ejercicio de aproximación a partir del estudio de las políticas sociales”, en Revista História da historiografía, No 14, 2014. Disponible en: <http://www.historiadahistoriografia.com.br/revista/ article/viewFile/771/444> [Consulta: 2 febrero 2015]. 
en el ámbito historiográfico argentino y extra argentino. ${ }^{6}$

El resultado ha sido el desarrollo de un conjunto de trabajos sobre distintas provincias, ciudades y regiones, así como líneas de investigación en curso sobre diversos temas situados en variados espacios locales $\mathrm{y}$ regionales, que reflejan cambios en aquel sesgo que reseñábamos al inicio. Por su parte, en algunos foros académicos se han insinuado debates sobre tal problemática, en particular el que refiere a la prioridad otorgada a los estudios de caso, locales o regionales frente a perspectivas que los conciben como una mera agregación de datos empíricos o mero "localismo" y, alternativamente, enfatizan la necesidad de formular nuevas síntesis o líneas de interpretación de alcance general, fortaleciendo la construcción de una "historia nacional".

Aún registrando la proliferación de estudios situados e incluso la emergencia de tales discusiones, consignaré que sólo limitadamente estos desarrollos han ido acompañados por una reflexión más profunda sobre uno de los problemas que atraviesa los estudios sobre el pasado reciente y que constituye el núcleo del presente dossier: el de

6. Véase, entre otros, TERRADAS I SABORIT, Ignaci, "La historia de las estructuras y la historia de la vida. Reflexiones sobre la forma de relacionar la historia local y la historia regional", en DALLA CORTE, Gabriela y FERNÁNDEZ, Sandra (compiladoras) Lugares para la Historia..., Op. Cit.; CASANOVA, Julián, "Historia local, historia social y microhistoria”, en RÚJULA, Pedro, PEIRÓ, Ignacio (editores) La historia local en la España contemporánea, L'Avenc, Barcelona, 1999; KNIGHT, Alan, "Latinoamérica: un balance historiográfico", en Revista Historia y Grafía, México, enero-junio de 1998, No 10; SERRANO ÁLVAREZ, Pablo, "Interpretaciones de la historiografía regional y local mexicana, 1968-1999”, en Revista de Historia Regional, México, 2001, № 6. sus escalas de análisis. En esta dirección, voy a detenerme en dos cuestiones conexas, que vinculan los estudios sobre el pasado reciente con el problema de las escalas de análisis.

Como se ha afirmado, las escalas de análisis no son neutras y tampoco están definidas de antemano, ${ }^{7}$ sino que las mismas constituyen una elección del investigador/a, vinculada con sus preguntas, su objeto de estudio, las dimensiones que pretende indagar, las fuentes con las que cuenta, etc. En tal sentido, la escala es una opción metodológica, ${ }^{8}$ una elección del investigador/a y la asunción de esa opción debería hacerse explícita, del mismo modo que se hace con la periodización. Tal perspectiva no es muy frecuente en el ámbito de la Historia Reciente, donde todavía predominan los trabajos que no enuncian el recorte espacial o la escala elegida, ni problematizan en torno a ello. ${ }^{9}$

7. Vid. el artículo de JENSEN, Silvina, LASTRA, Soledad, contenido en este dossier.

8. En palabras de Pons y Serna: "Una escala es una categoría que se adopta con la finalidad de aprehender una realidad y lograr representarla. En otras palabras, el historiador al optar por una escala está tomando una decisión explícita respecto a la cantidad y al tipo de información que considera adecuada para alcanzar su propósito. En consecuencia no existe una relación lineal entre lo que el historiador se propone estudiar y las modalidades más apropiadas que tiene para representarlo". Vid. PONS, Anaclet y SERNA, Justo, "Más cerca, más denso: la historia local y sus metáforas", en FERNÁNDEZ, Sandra (compiladora) Más allá del territorio..., Op. Cit., p. 25.

9. Similares consideraciones realizamos respecto del uso de conceptos y definiciones para caracterizar la violencia política y la represión en la historia argentina reciente. Al respecto, vid. ÁGUILA, Gabriela, "La represión en la historia reciente argentina: perspectivas de abordaje, conceptualizaciones y matrices explicativas", en Contenciosa. Revista sobre violencia politica, represiones $y$ resistencias en la historia iberoamericana, Santa Fe, $2^{\circ}$ semestre 2013, Año 1, No 1. Disponible en: <http://www. contenciosa.org> 
El segundo señalamiento refiere a los abordajes a escala local-regional. Los estudios de caso o, más específicamente, los estudios locales o regionales no se justifican por su mero valor de agregar más información o más empiria, y/o por su poder de verificación de una historia "nacional", sino que su principal ventaja radica en el potencial explicativo que poseen, en la posibilidad que presentan, al achicar el foco, de complejizar o hacer más denso el estudio y la explicación sobre un problema o tema específico. ${ }^{10}$

En el momento actual de la Historia Reciente en la Argentina, quedan pocas dudas de que se requieren estudios de caso, situados o no, en primer lugar porque existen enormes vacíos en términos de la construcción de conocimiento histórico sobre tales períodos y problemas. Pero, asimismo, por el modo en el cual se ha constituido aquel campo de estudios: la historia del pasado reciente ha estado desde sus inicios formateada por grandes interpretaciones de tipo macro-analíticas (sea por la vía de las perspectivas provistas por la sociología o la politología, tanto como por la vía de los estudios sobre la memoria), que deben ser confrontadas, puestas en tensión y complejizadas con estudios más densos sobre casos y espacios locales y regionales. Y, vinculado con ello, con una problematización sobre las escalas del análisis.

A mi juicio, los aportes potenciales no sólo provendrán de los estudios situados a escala local y/o regional, que necesariamente deberán ser puestos en diálogo con los producidos para

10. SERNA, Justo y PONS, Anaclet, "Más cerca, más denso: la historia local y sus metáforas", en FERNANDEZ, Sandra (compiladora) Más allá del territorio..., Op. Cit. otros espacios o las perspectivas de alcance nacional, sino también de otros juegos o variaciones de la escala: concibiendo a la región en un plano no estrictamente ajustado al territorio nacional (conosureña, por ejemplo), atendiendo a la escala trasnacional -tal como lo vienen mostrando los estudios sobre exilio o sobre el movimiento de derechos humanostanto como perspectivas de análisis comparado que desbordan el espacio nacional y permiten iluminar procesos de violencia política y terror estatal como los acaecidos en el pasado reciente argentino. ${ }^{11}$

Finalmente, no debería perderse de vista que la elección de la escala muchas veces se vincula con la disponibilidad y/o el acceso a determinadas fuentes o corpus documentales. Con todo y las limitaciones que se verifican en términos de la ausencia de una política nacional de archivos, las restricciones al acceso o las enormes diferencias existentes en las distintas provincias y ciudades, es un dato cierto que en los últimos años se han acrecentado los archivos y fondos disponibles para la investigación sobre el pasado reciente, muchos de los cuales son archivos provinciales o locales (en particular vinculados con los distintos niveles del estado y/o sus agencias). ${ }^{12}$

11. Vid. ALONSO, Luciano, "Dictaduras regresivas y represiones en Iberoamérica: trayectorias particulares y posibilidades de comparación”, en ÁGUILA, Gabriela y ALONSO, Luciano (coordinadores) Procesos represivos y actitudes sociales: entre la España franquista y las dictaduras del Cono Sur, Prometeo, Buenos Aires, 2013.

12. Un repaso sobre la problemática de los fondos y archivos para los estudios sobre el pasado reciente en ÁGUILA, Gabriela, "Estudiar la represión: entre la historia, la memoria y la justicia. Problemas de conceptualización y método", en FLIER, Patricia (compiladora) Dilemas, apuestas y reflexiones teórico-metodológicas para los abordajes en Historia Reciente, Ediciones FAHCE, Universidad Nacional de La Plata, 2014. Disponible en: <http:// 
Esa disponibilidad no aparece sólo como una invitación a hacer historia local y regional sino que muchas veces es casi un imperativo para realizar investigaciones atendiendo a esas escalas.

Todo ello sin dejar de consignar que los estudios de caso o los abordajes a escala localregional adquieren significación siempre $\mathrm{y}$ cuando contribuyan a explicar el problema más general, con vistas a la construcción de una historia integradora que no pierda de vista, más allá de las especificidades, la totalidad del proceso histórico. Una perspectiva que no renuncie a la posibilidad de brindar explicaciones amplias, sintéticas y totalizadoras y a construir narrativas más complejas y comprensivas de los procesos analizados.

Con ese horizonte y esas preocupaciones, este dossier pone el foco en el problema de las escalas de análisis, recogiendo artículos que abordan contextos y procesos represivos acaecidos en el pasado reciente en Argentina y otros países, y que apelan a diferentes escalas de observación y análisis.

El trabajo de Silvina Jensen y Soledad Lastra sobre los exilios políticos argentinos en el pasado reciente constituye un ejemplo acabado del uso reflexivo de las escalas de análisis para abordar una problemática transitada de modos muy diversos. Partiendo de la perspectiva sostenida por Bernard Lepetit, respecto de que las escalas han sido vividas y moldeadas por el comportamiento de los actores sociales del pasado, proponen pensar al exilio como un "objeto poliédrico", que requiere ser estudiado desde distintos niveles y escalas de análisis. Las autoras revisan la

$\overline{\text { libros.fahce.unlp.edu.ar/index.php/libros/catalog/ }}$ view/30/45/119-1>. producción existente sobre los exilios políticos desde las perspectivas comparadas, los estudios transnacionales y las redes, explorando con solvencia sus potencialidades y limitaciones analíticas y explicativas.

Por su parte, el artículo de Luciano Alonso sistematiza algunas de sus indagaciones sobre la movilización pro derechos humanos, con el objetivo de identificar escalas de análisis $\mathrm{y}$ dimensiones de acción e integración social diversas. Así, pone en cuestión la narrativa "clásica" construida desde la zona capitalina, atendiendo a las variaciones locales y regionales en la constitución y actuación de los organismos defensistas. Y a la vez que alerta sobre las explicaciones reduccionistas, releva las dimensiones continentales, globales $\mathrm{y}$ trasnacionales del movimiento de derechos humanos.

Los textos de Ana Belén Zapata y Santiago Garaño son una muestra representativa de la ampliación de las indagaciones a escala local-regional, en estos casos centradas en el ejercicio de la represión estatal y paraestatal $\mathrm{y}$ sus efectos. En un trabajo que complejiza visiones generalizadoras sobre la violencia política paraestatal, Zapata reconstruye las tramas represivas en la ciudad de Bahía Blanca en los años previos al golpe de estado de 1976, poniendo en diálogo procesos políticos nacionales con las particularidades locales del accionar paraestatal y sus articulaciones con las fuerzas represivas y el ámbito político. Por su parte, Garaño explora con originalidad y solidez teórica y analítica una de las últimas fases del Operativo Independencia. En su trabajo centra su estudio en la fundación de varios pueblos en el pedemonte tucumano, analizando la faceta "productiva de relaciones 
sociales y de nuevas espacialidades" que asentó el dominio del Ejército sobre un espacio disputado entre las fuerzas represivas y la guerrilla rural.

El dossier se completa con dos artículos producidos por reconocidos especialistas extranjeros, a propósito de los pasados recientes de Chile y España, no por ello ajenos o lejanos a problemas abordados por la Historia Reciente argentina. Verónica Valdivia Ortiz de Zárate analiza los procesos de regionalización y municipalización impulsados por la dictadura pinochetista, con el objetivo de explicar sus perdurables efectos en términos sociales y políticos. La autora despliega los mecanismos utilizados en el caso chileno para obtener la despolitización de la sociedad, basados no sólo en el terror y el neoliberalismo, sino también en el "escalonamiento decisional", posibilitado por la regionalización y la municipalización.

En último término, Carme Molinero y Pere Ysás ponen el foco en el proceso de transición a la democracia en España, partiendo de la perspectiva de que la nutrida bibliografía existente sobre la problemática no ha prestado atención suficiente a la dinámica desarrollada entre centro y periferia. Así, revisan críticamente el relato hegemónico construido sobre la transición, para luego explorar con agudeza las relaciones y tensiones entre el devenir nacional y el proceso político en la periferia peninsular (en particular en Cataluña y el País Vasco) entre la crisis del franquismo y los inicios de la transición.

Como fue dicho, el propósito de este dossier era reunir un conjunto de textos que refirieran, desde perspectivas diversas, al problema de las escalas de análisis en la Historia Reciente. En tal sentido, no pretende concluir o agotar con esta presentación las múltiples posibilidades que la temática convoca, sino más bien espera contribuir a la problematización, la utilización reflexiva y el necesario debate -aún en ciernessobre las escalas de análisis utilizadas para abordar el pasado reciente argentino.

Recibido: 18/05/2015 Aceptado: 30/06/2015 Publicado: 31/07/2015 